\title{
ECONOMIC FRAMEWORK OF THE BIO-BASED PRIMARY SECTOR IN BULGARIA
}

\author{
N. Markov* \\ Department of Regional Development, Faculty of Economics, Trakia University, \\ Stara Zagora, Bulgaria
}

\begin{abstract}
The effective management of bioeconomy requires a structural and dynamic analysis of the primary sector. The aim of the present study is to gauge the size of the bio-based primary sector in Bulgaria. Results indicate that in Bulgaria the capacities of the bio-based sector are not used rationally. Conclusions are intended to define national priorities and policies in the area of bioeconomy.
\end{abstract}

Key words: bio-economy, input-output, sectoral analysis

\section{INTRODUCTION}

The expected increase of the world population to over 9.5 billion people (until 2050) combined with the changing needs of consumerist societies will determine global victualling security as a crucially important economic factor in the near future. Simultaneously, the world's arable land constantly decreases due to soil degradation and the extension of living areas. Climate changes will enhance the process of land loss. In industrialized nations an increase in eating disorders, such as obesity, diabetes, allergies, cardio-vascular diseases is likely to continue steadily. This will have high social consequences, including a rise in healthcare costs (1).

A very important factor that has an impact on the development of organic farming is the increase of market value of biological production and especially the increase in the demand for organic products. On the whole, it is evident that organic farming forms a specific market niche on the world and European agricultural market. Its development is related especially to the new trends in consumption, as well as to the economical growth of certain states, mostly to the increase in income per capita in these countries (2).

\footnotetext{
*Correspondence to: Nedelin Markov, Department of Regional Development, Faculty of Economics, Trakia University, Stara Zagora, University Campus,n_markov@uni-sz.bg, +35942699436
}

The terms bioeconomy and bio-based economy refer to some of the most important political and economic concepts in Europe and are related to the replacement of fossil resources with bio-based resources (3). Europe's bioeconomy involves the production of reusable biological resources and the conversion of these resources and residues into products with an added value such as food, fodder, bio-based products and bioenergy (4). The rational use of bioresources is a strong instrument for the regulation of these processes, as well as for the reduction of the consequences from negative trends on a global and regional scale. Bioeconomy defines a new circle of economic and social relations which remain external to the production concepts of the past. The economic effects of the use and respectively the irrational exploitation of the primary biosector can lead to the accumulation of short-term and long-term competitive advantages and disadvantages. The aim of the present study is to outline an economic framework of the primary biosector in Bulgaria which shall lead to some conclusions and recommendations regarding the subject matter of the study.

\section{METHODS}

In our study we have used standard analytical instruments typical for measuring the volume and structure of a specific object. The study follows the official definition of bioeconomy which was published in COM (2012) 60 of the 
European Commission (5). The specific point is that information media is based on inputoutput tables. The general conceptual framework of the input-output tables in Bulgaria has been developed and upgraded with respect to the internationally accepted methodological principles and standards of the European system of national and regional accounts (ESA'95) for the tables of 2010, and ESA'2010 for the tables after 2010 publications of Eurostat, respectively of the System of national accounts (SNA'93 and SNA'2008) - a joint publication of UN, OECD, Eurostat, IMF and the World Bank. The input-output tables represent an integrated part of the annual national accounts and deliver a final balanced version of the economic categories within the GNP - a detailed structure of groups of products and services, types of economic activities, and types of categories of end consumption. They have been developed on the basis of the concepts and definitions of ESA'95 and ESA'2010 for treating transactions, economic subjects, classification principles of grouping statistical units in the way they are applied in the other development services of national accounts. This type of information sources has one very serious flaw which can be found in data's periodical update. Data is updated not earlier than 36 months since the end of the reference period. In the year of writing this study (2019) the most recent data refers to 2014. This slow processing and listing of data hinders the derivation of adequate conclusions and recommendations because they refer to events which in midterm plan could have been remodeled in a certain direction.
MARKOV N.

The focus of study is directed to the so-called primary biosector. It comprises the Agriculture, forestry and fisheries sector. It is separated into the following sections:

- Plant production, animal breeding and hunting

- Forestry

- Fisheries

This sector simultaneously produces and consumes bio products and also sees bio resources as a result of its ordinary activity, which is at the basis of bioeconomy. From the analysis we have selected the processing industry and other sectors which produce organic products. The basis of the analysis is presented with the following equation:

$\sum$ Agr. prod $=$ Asect + Bsect $+\cdots \cdots+$ + isect Where:

Agr.prod - produce of the primary biosector (agricultural, forestry and fisheries);

Asect - consumption from sector A;

Bsect - consumption from sector B;

The following matrix illustrates the same sum as:

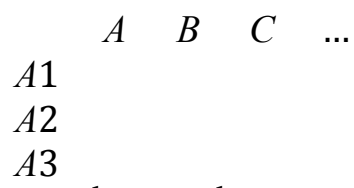

Each column shows the consumption of products by the subsectors of the bio primary sector (A1, A2, A3).

\section{RESULTS}

In Table 1 we have shown some basic indicators describing the volume of two different primary sectors - primary biosector (agriculture, forestry and fisheries) and primary non-biosector, presented by the socalled extractive industry (including coal, oil, gas, mining and other raw materials).

Table 1. Main indicators of bio and non-bio sectors in Bulgaria for 2010 and 2017

\begin{tabular}{|c|c|c|c|c|c|c|c|c|}
\hline & & & 2010 & & & 2017 & & \\
\hline & & & Enterprises & Employees & $\begin{array}{l}\text { Income } \\
\text { from the } \\
\text { activity }\end{array}$ & Enterprises & Employees & $\begin{array}{l}\text { Income } \\
\text { from the } \\
\text { activity }\end{array}$ \\
\hline & & & number & number & $\begin{array}{l}\text { BGN in } \\
\text { thousands }\end{array}$ & number & number & $\begin{array}{l}\text { BGN in } \\
\text { thousands }\end{array}$ \\
\hline A & $\begin{array}{l}\text { AGRICULTURE, } \\
\text { FORRESTRY } \\
\text { AND FISHERIES }\end{array}$ & Total & 13341 & 76958 & 5782185 & 19880 & 86888 & 9877052 \\
\hline B & $\begin{array}{l}\text { EXTRACTIVE } \\
\text { INDUSTRY }\end{array}$ & Total & 403 & 24788 & 2502713 & 374 & 21843 & 3048475 \\
\hline
\end{tabular}

Source: National Statistical Institute 
MARKOV N.

The table illustrates the large volume of the organic sector. For 2010 the organic sector is twice as, and in 2017 - three times as prevalent with respect to the indicator "Income from the activity". The sector is characterized by a large number of small enterprises in which 4.5 people on average are employed. In the nonbio sector a concentration of a small number of enterprises is observed, in which 60 people on average are employed. The enterprises in the agricultural, forestry and fisheries have comparatively equal territorial distribution in the country, while the enterprises from the extractive industry are located in proximity to the raw material obtained.

In Table 2 the consumption of products from the primary biosector is presented according to the defined methodology.

Table 2. Matrix of the use of products from the primary biosector in 2014

\begin{tabular}{|c|c|c|c|c|c|c|c|c|c|c|c|c|}
\hline Economic activities & 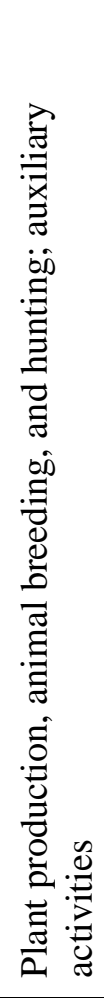 & $\begin{array}{l}\widehat{G} \\
0 \\
0 \\
0 \\
0\end{array}$ & 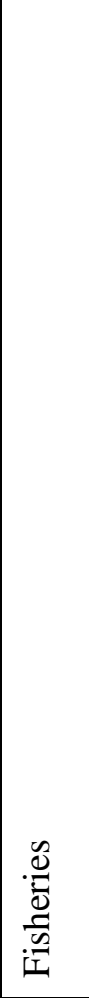 & 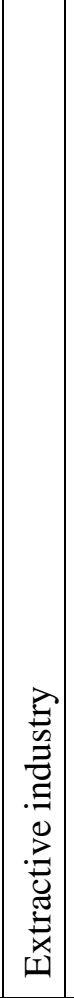 & 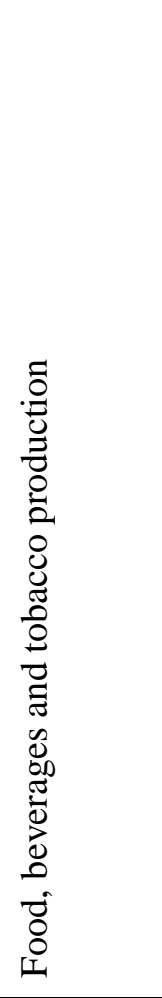 & 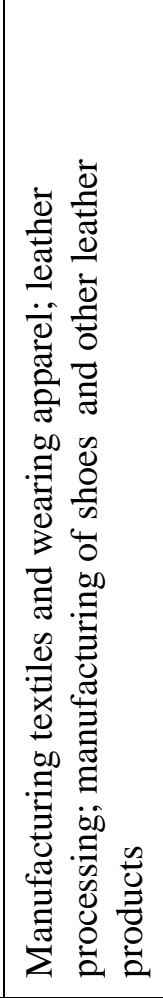 & 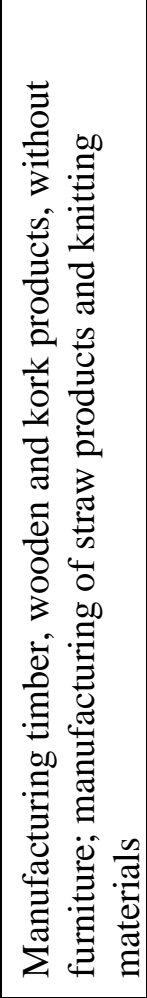 & 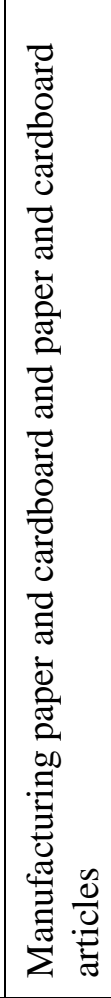 & 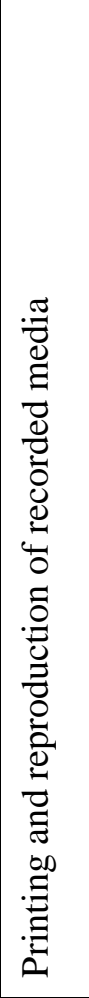 & 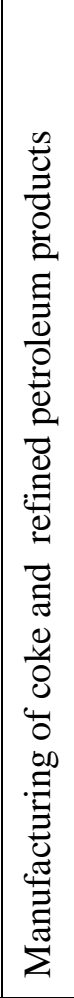 & 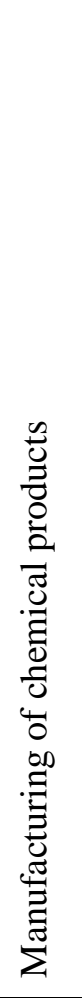 & $\begin{array}{l}\frac{\infty}{\Delta} \\
\stackrel{ \pm}{0}\end{array}$ \\
\hline & A01 & A02 & A03 & B & $\mathrm{C} 10-\mathrm{C} 12$ & $\mathrm{C} 13-\mathrm{C} 15$ & C16 & $\mathrm{C} 17$ & $\mathrm{C} 18$ & $\begin{array}{l}\mathrm{C} 1 \\
9 \\
\end{array}$ & $\mathrm{C} 20$ & \\
\hline & 1 & 2 & 3 & 4 & 5 & 6 & 7 & 8 & 9 & 10 & 11 & \\
\hline $\begin{array}{l}\text { Plant production, } \\
\text { animal breeding, and } \\
\text { hunting; auxiliary } \\
\text { activities }\end{array}$ & $\begin{array}{l}2 \\
195\end{array}$ & 6 & & & 1321 & 15 & 1 & & & & 112 & 238 \\
\hline $\begin{array}{l}\text { Forestry production } \\
\text { and related services }\end{array}$ & 24 & 160 & & & 38 & 2 & 165 & 21 & & & 1 & 63 \\
\hline $\begin{array}{l}\text { Fish and other water } \\
\text { organisms and } \\
\text { products; related } \\
\text { services }\end{array}$ & & & 4 & & 31 & & & & & & & 24 \\
\hline
\end{tabular}

Source: National Statistical Institute

It is evident from the presented data that plant production, animal breeding and hunting are credited with the largest consumption, while food industry comes second. As for forestry, the situation is almost similar with the exception that the other big consumer of production is Timber and related articles. Fish production's main consumer is food industry.

Figure 1 shows the structure of the produced articles of the largest bio primary sector, namely - plant production, animal breeding and hunting. 


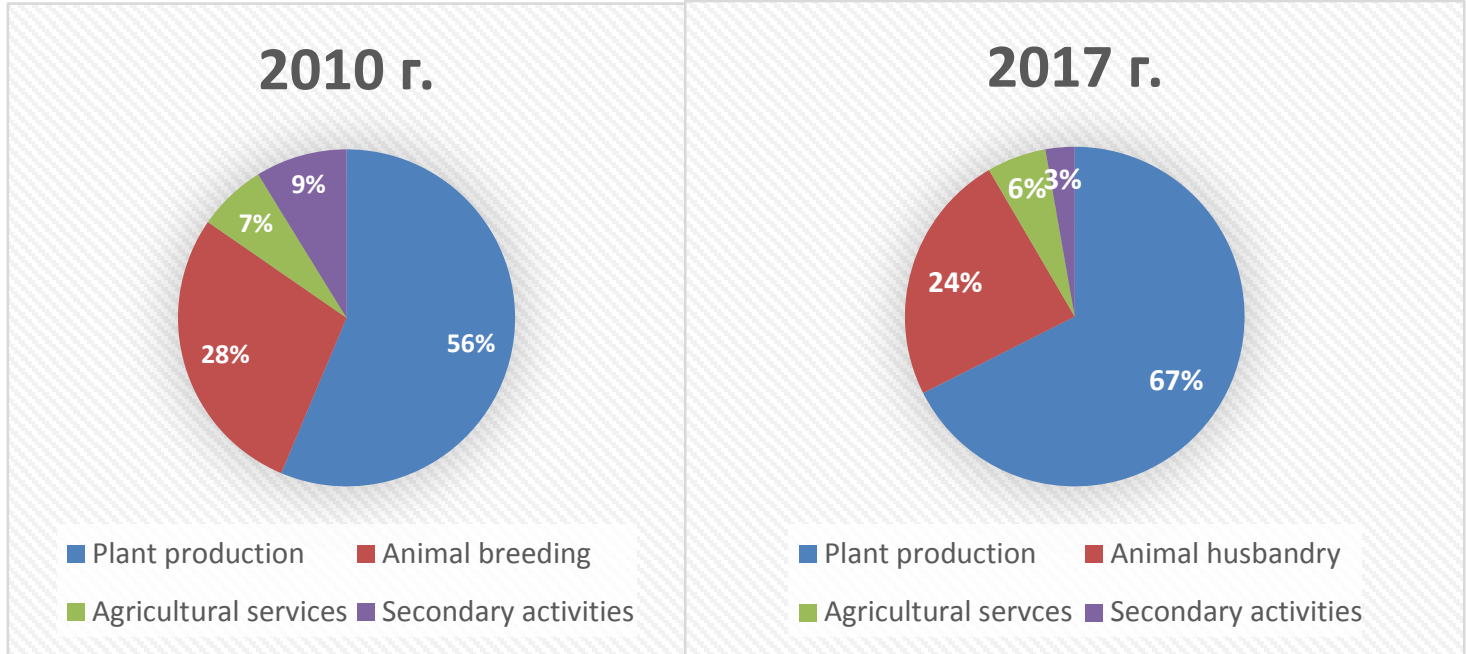

Figure 1. Structure of agricultural production for 2010 and 2017.

Source: National Statistical Institute

The data in Figure 1 shows that a change in the structure of the agricultural production can be observed. The production of plant products has increased to compensate the reduction of animal products. A real decrease is noted in the so-called secondary activities.
Figure 2 shows information about the production base of the bio primary sector. The data present the gross capital employed and its consumption.

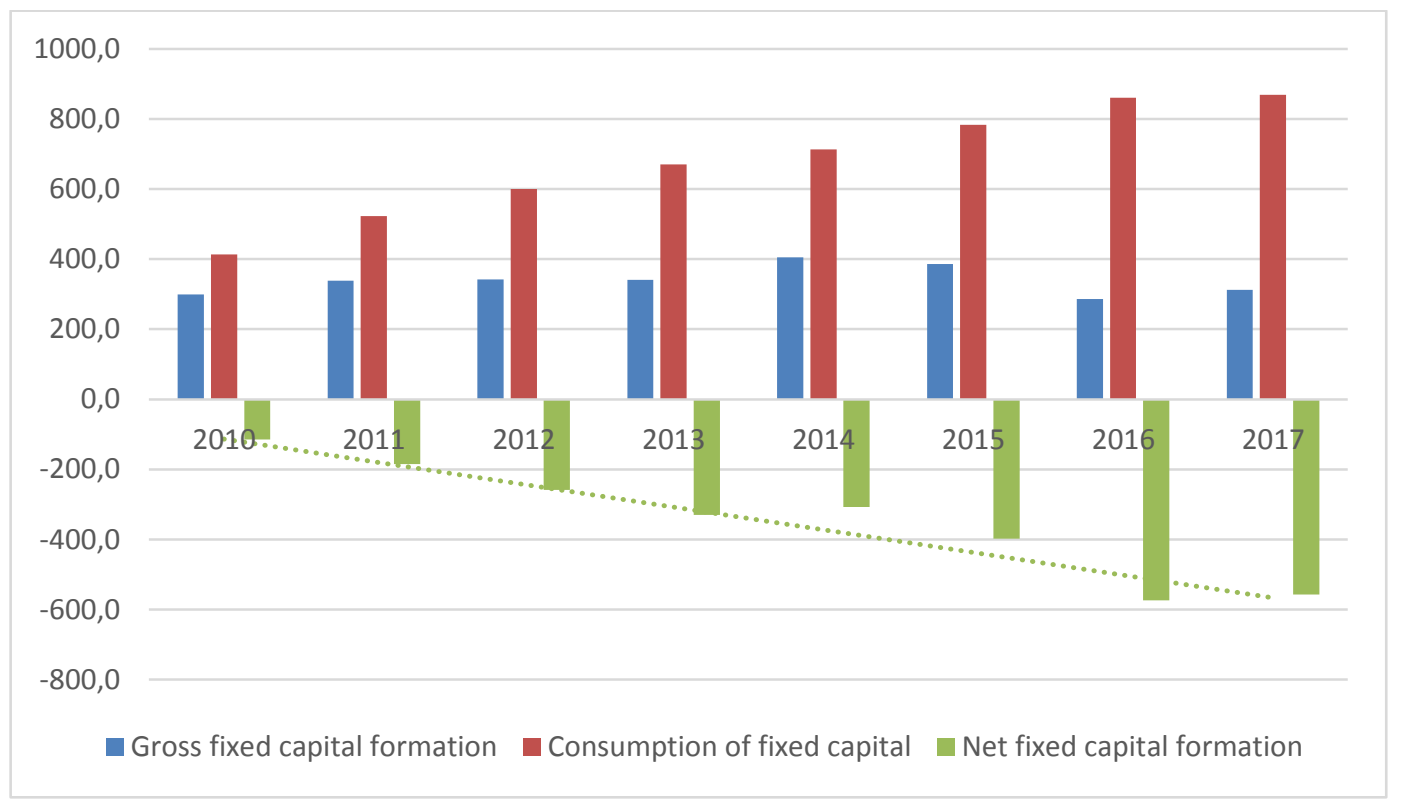

Figure 2. Gross fixed capital formation in the bio primary sector

Source: National Statistical Institute

Figure 2 shows that there is a negative net capital formation. This is surprising because since 2007 solid resources have been invested in the Bulgarian agriculture (originating from EU funds). A possible explanation for this growing trend is that the main capital was accumulated in the first years after Bulgaria's accession to the EU. Furthermore, it is possible that bio primary sector may have its idiosyncratic capacity which does not allow a rather strong development and increase of investment costs.

As for the structure of the general consumption of the biosector production, data reveal that the first place is taken by the export of ready produce. Only for four years (2010-2014) the export of primary bioproducts has increased by over $50 \%$. This is a significant rise and shows the competitiveness of Bulgarian producers on international markets. A worrying trend, however, is that this increase in the export is 
not a result of a growth in the biosector, but rather due to a decrease of firm consumption which shows shrinking, mostly in the food and beverages and animal breeding sectors.

The analysis of the input-output tables leads to observing some interesting trends. The consumption of primary bioproducts from the Chemical products sector has risen approximately 60 times. This huge increase is due to the production of essential oils. Bulgaria has long traditions in growing medicinal and aromatic plants and the production of essential oils. Its export orientation has turned this sector into Bulgaria's emblematic industry. The growing application of essential oils in the light industry (cosmetic, medicinal, food and beverage, etc.) and the fast development of aromatherapy have fostered the demand for oils in the world in the years following the economic crisis of 2007-2011. The global market of essential oils is expected to grow with an average annual pace of accumulation of $8-11 \%$ in this period. Moreover, another reason for this fast growth is EU assistance. For the period of 2014-2020, 50 new project applications focusing on essential oils production have been submitted. The total value of $\mathrm{EU}$ assistance is over BGN 20 million, while the planned costs in the sector are twice as much (6).

\section{CONCLUSION}

Despite market challenges and the development of a system of support for the primary biosector, several unused possibilities remain unexplored. Such is the production of electricity. The consumption of primary products for the production of electricity in 2014 versus 2010 is only 4.8 million. The estimates show that the role of biomass in the energy balance will increase, but there will not be a significant rise in the used quantities of biomass. The higher efficiency of biomass will be achieved in two directions: an increase of its share in the end energy consumption and an increase of the efficiency of the end energy transformations through innovative burning technologies. This suggestion should be aligned with a number of social, environmental and other non-profit factors which determine the framework of the policy for sustainable economic development.

Another direction for ready bioproducts is pharmaceutical production, as well as the introduction of contemporary methods for processing and reuse of residues of bioproducts.

The following conclusions can be made on the basis of the high potential:

1. Creating a working national strategy with a horizon not less than 10 years in which a balance between sustainable development and the production capacities of the society is implemented.

2. Significant investments in education and research, as well as internationalization of research.

3. Normative regulation of the economy envisioning the introduction of bioprimary sector products.

4. Export of bioprimary products has a very high share. Their processing must be stimulated and products with a higher degree of readiness and added value should be exported. This requires an increase in the competitiveness of Bulgarian economy and investment in contemporary technologies.

\section{ACKNOWLEDGEMENT}

We wish to acknowledge the support of National Scientific Program "Healthy Foods for Strong Bioeconomics and Quality of Life" of the Ministry of Education and Science, Bulgaria funding our work on developing the article.

\section{REFERENCES}

1. Bundesministerium für Bildung und Forschung, Nationale Forschungsstrategie Bio Ökonomie 2030, Unser Weg zu einer bio-basierten Wirtschaft, p.4, Deutschland, 2010

2. Branzova, P., Organic Farming in Bulgaria and EU-Comparative Dimensions, Economic Studies, p.183-187, 2019

3. Staffas, L., Gustavsson, M., McCormick, K., Strategies and policies for the bioeconomy and bio-based economy: an analysis of Official National Approaches. Sustainability 5 (6), 2751-2769, 2013

4. European Commission. Innovating for Sustainable Growth: A Bioeconomy for Europe; COM(2012) 60 Final, European Commission: Brussels, Belgium, p. 9, 2012

5. Eurostat. NACE Rev. 2 Statistical Classification of Economic Activities in the European Community; Eurostat. Methodologies and Working Papers: Luxembourg, p. 367, 2008

6. Inteliagro. Essential oil production in Bulgaria , p.4, 2007 